\title{
El desarrollo de la tecnocracia en Chile y su impacto en las políticas de Estado, durante la primera mitad del Siglo $X X$
}

doi: 10.33264/rpa.202001-02

Diego Abel Durán Toledo

Secretario Académico de la carrera de Administración Pública de la Universidad

Autónoma de Chile y Docente del Instituto Profesional AIEP

\section{Resumen}

El presente texto, analiza el devenir histórico de la consolidación del aparato público estatal chileno durante la primera mitad del siglo XX, principalmente en base al accionar de los tecnócratas, como el grupo de profesionales que pudieron construir las bases de la administración pública nacional actual, a través de la implementación de sus mecanismos racionales de gestión, en el contexto de una disputa con los grupos tradicionales de poder.

Lo anterior se tradujo en cambios fundamentales en la forma de entender la razón de ser del Estado y en el cómo a través de principios de la tecnocracia, se pudieron realizar transformaciones importantes en las diferentes áreas de la gestión pública, dotando a la nación durante décadas de un proyecto nacional e institucional común, el cual tenía como finalidad última generar cambios fundamentales en la calidad de vida de sus ciudadanos.

Palabras claves: Tecnócratas, Estado, gestión pública, proyecto país, principios fundamentales racionales y cambio social

\section{Abstract}

This text analyzes the historical evolution of the consolidation of the Chilean state public apparatus during the first half of the 2oth century, mainly based on the actions of technocrats, such as the group of professionals who were able to build the foundations of the current national public administration, through the implementation of its rational management mechanisms, in the context of a dispute with traditional power groups.

This resulted in fundamental changes in the way of understanding the raison d'être of the State and in how, through the principles of technocracy, important transformations could be made in the different areas of public management, endowing the nation for decades of a common national and institutional project, whose ultimate goal was to generate fundamental changes in the quality of life of its 
citizens.

Keywords: Technocrats, State, Public Management, country project, rational fundamental principles and social change

\section{Introducción}

El aparataje público del Chile de comienzos del siglo XX se caracterizaba por su escaso desarrollo en materias ajenas a términos de seguridad nacional y provisión de algunos servicios básicos.

En este contexto, surge la figura de los tecnócratas, los cuales son "individuos de clara orientación técnico-científica y que logra adquirir influencia política en altos círculos de gobierno debido a su posesión de habilidades especializadas en los terrenos de las políticas económicas, las finanzas y la administración del Estado. Sin embargo, él aclara que el poder político que pueden alcanzar los tecnócratas no es permanente y que éste siempre se encuentra subordinado al poder de los políticos que rigen el rumbo de los gobiernos. Más que poder político en sí se trataría de "influencia política" que ejercen sobre los mandamases, entregando consejos sobre complejas materias económicas y de políticas públicas" (Meynaud, 1968, pág. 70.)

En el presente texto se demostrará el papel vital que jugó este grupo profesional, en la configuración de las bases de la administración pública nacional actual, proceso que no estuvo exento de múltiples vicisitudes y dificultades.

Los objetivos que este artículo persigue son en primer lugar, ilustrar la evolución del estamento tecnocrático y desatacar los conflictos iniciales que este grupo de profesionales tuvo que enfrentar ante la élite política tradicional para la consolidación de una administración estatal basado en criterios de racionalidad y eficiencia. Por otra parte, este texto también se encargará de resaltar el rol de los cuerpos tecnocráticos en la constitución de una visión común de país, en el contexto del modelo del Estado de Bienestar chileno durante la primera mitad del siglo XX. Finalmente, analizará una serie de asuntos conceptuales respecto a principios fundamentales de la tecnocracia, como forma de administrar el Estado.

\section{Tecnócratas versus Políticos: Tensiones sobre el manejo del gobierno y el devenir del Estado.}

Durante los inicios del Siglo XX, existió una fuerte pugna entre los cuerpos tecnocráticos y los diferentes partidos políticos de la época, sobre el devenir institucional del Estado Chileno. 
Dicho conflicto no solamente responde a la realidad política, económica y cultural de la primera mitad del siglo pasado, sino también a un patrón de desarrollo común que se mantiene inclusive en la actualidad, ya que "la relación entre políticos y tecnócratas también ha estado plagada de conflictos en donde los primeros han intentado cortar el paso al ascenso tecnocrático que se lo ve como una amenaza directa a sus posiciones de poder al interior del sistema político. Lo que vemos es que el ascenso tecnocrático se ha visto favorecido por el desperfilamiento de los partidos políticos". (Silva, 2006, pág. 180.)

Cabe señalar, que no solamente estas diferencias generales que son transversales a todas las épocas, se limitan a una lucha por el poder del Estado, sino que también a un "choque ideológico" sobre la concepción del manejo del gobierno, lo cual se debe a que "mientras los tecnócratas creen que la legitimidad se mantiene de mayor forma a través de una administración profesional y el uso de criterios técnicos en la toma de decisiones, los políticos piensan que la legitimidad del régimen se sustenta de la preservación de viejos idearios nacionales y la toma de decisiones siguiendo lineamientos políticos" (Silva, 2006, pág. 180).

El Chile de comienzos del siglo $X X$, no era ajeno a este tipo de conflictos, desde inclusive a mediados del siglo XIX, han existido fuertes tensiones entre los sectores tecnocráticos y políticos por el dominio del aparataje estatal. Estos primeros atisbos de crítica, sobre la forma en que la "clase aristocrática y política" ha manejado los asuntos del gobierno, se sustentan sobre la base del apoyo recibido por los postergados sectores medios, los cuales eran relegados de las grandes cúpulas del poder cooptadas por la aristocracia terrateniente chilena. Esta incipiente clase media, defendía los "principios mesocráticos tales como la valoración al mérito, el esfuerzo personal y los estudios, por sobre las ventajas de alcurnia" (Silva, 2010, pág. 42).

Estos conflictos, se acentuaron posteriormente con el escenario social y económico que existió en el país entre 1925 y 1930, caracterizado por un lado por la existencia de clases acomodadas nacionales producto de sus posesión de tierras, de una estructura económica netamente mono productora e íntegramente dependiente del salitre; el cual a su vez constituía por impuestos de producción y exportación gran parte del erario público, la presencia de una creciente clase media, ávida de participación política y por último la existencia de una clase relegada que vivía y trabajaba en condiciones infrahumanas, lo cual se acentuó con la crisis del salitre en los años 20's y la decadencia del régimen parlamentario.

En este escenario, y en especial con la llegada de Carlos Ibáñez del Campo al gobierno 
en 1927, debido a un creciente sentimiento de desconfianza hacia los partidos políticos tradicionales y amparados por un mandatario cuyo origen estaba lejos de dichas cúpulas de poder, se generó la ventana de oportunidad para que los tecnócratas pudieran acceder (como nunca antes) a posiciones poder, desplazando a los cuerpos políticos de las oficinas gubernamentales, estos cambios "fueron legitimados por argumentos que destacaban la necesidad de alcanzar la eficiencia y la excelencia técnica en el manejo de los asuntos del Estado" (Silva, 2010, pág. 73).

Este hecho, se enmarca en la postura del Presidente Ibáñez y de su ministro de Hacienda Pablo Ramírez, los cuales creían en la necesidad de generar una Administración Pública "renovada y desligada de los debates y combinaciones parlamentarias", y así mismo entendió la administración pública ligada al "concurso de técnicos que utilicen métodos administrativos para la ejecución de la política" (Ibáñez Santa María, 1983, pág. 54).

Esta idea, se fundamentaba en "la necesidad de construir lo que él llamaba un Estado fuerte y eficiente" (Silva, 2010, pág. 74.)

El gobierno ibañista, genera un discurso profundamente anti partidista, el cual propiciaba el manejo de los asuntos del gobierno a profesionales técnicos con vastos conocimientos materias de administración, en este contexto el ministro Ramírez jugo un rol preponderante, debido a que "se encargó personalmente de la lucha contra la corrupción y la mala gestión en la administración pública” (Silva, 2010, pág. 85).

Posteriormente, la lucha entre los políticos y tecnócratas se trasladó al plano de la industrialización nacional, principalmente con el proyecto de creación y funcionamiento de la Corporación de Fomento de la Producción. (CORFO), bajo la administración del Presidente Pedro Aguirre Cerda. Dicha pugna, radicaba en la forma de operar de esta institución, mientras por un lado la derecha política (que no formaba parte de dicho gobierno del partido radical), promovía que existiese una dependencia política en el desarrollo de la labor de la Corporación, basado según Silva 82010) en que la CORFO debía presentar cada proyecto de desarrollo al Congreso para su aprobación.

Por otro lado, el gobierno apoyado por sectores de funcionarios técnicos presentes en la administración del Estado, propiciaban que este ente, funcionara netamente por criterios racionales definidos por el grupo de tecnócratas que desempeñaban sus labores en esta institución, generado de esta forma una "autonomía de la CORFO del gobierno, así como del Congreso y de los grupos empresariales" (Ibáñez Santa María, 1983, pág. 94). Esta disputa finalmente, fue resuelta mediante un acuerdo político entre la oposición y el gobierno del "Frente Popular", mediante el cual se garantizó efectivamente que la CORFO funcionara como un organismo independiente, en el 
cual los tecnócratas eran "amos y señores "de la institución, siendo alabados por diversos actores en su labor, ya que "los tecnócratas de la CORFO, gozaban de un amplio respeto : en varias oportunidades, la SOFOFA expresó su plena satisfacción con el equipo técnico a cargo de la CORFO" (Silva, 2010, pág. 118)

\section{La construcción de un proyecto país, bajo la óptica de los cuerpos tecnocráticos en Chile}

Uno de los roles fundamentales a las diferentes personalidades tecnócratas que han desempeñado funciones en la gestión del gobierno, es la de ser propulsores y transformadores sociales en Chile, principalmente porque las políticas formuladas y/o respaldadas por estos grupos, han producido un cambio en el devenir histórico de la nación. Para entender la importancia de los tecnócratas en la generación de un "proyecto país", es necesario realizar un recopilación del pensamiento de este grupo de personas, el cual data de mediados del siglo XIX con los postulados de Lastarria.

José Victorino Lastarria, fue el propulsor del "positivismo científico" a nivel nacional en la toma de decisiones en los asuntos del gobierno, doctrina que propugnaba una reforma significativa en el aparataje público y que abogaba por un pensamiento racional como factor preponderante en la conducción de la gestión pública, en base a la cual" los conocimientos científicos sobre la naturaleza y funcionamiento de la sociedad (basada en lecturas de Comte y Spencer) deberían constituir la base del proceso de toma de decisiones a nivel político-administrativo de la nación" (Silva, 2010, pág. 42). Cabe señalar que el proyecto tecnocrático, no solo representaba en sus inicios el ideario de un grupo de intelectuales liberales que propugnaban la racionalidad como forma de administrar el Estado, sino que también representaban los anhelos de una clase social determinada, principalmente porque en base a este proyecto "se alimentó especialmente de las expectativas y anhelos de los sectores medios que empezaron a surgir a mediados del siglo XIX". (Silva, 2010, pág. 42). Posteriormente Valentín Letelier, complementó esta noción de la generación de una administración pública racional y meritocrática, dotándola de iniciativas que esta debía impulsar para garantizar el bienestar nacional y atender a las necesidades de las amplias masas olvidadas de la historia chilena.

Es en base a esta idea, que el Estado jugaba un papel preponderante, el cual debía satisfacer las necesidades sociales de las grandes mayorías con la finalidad de garantizar una mejora sustantiva en la calidad de vida de las personas, dentro de un marco institucional estable. Uno de los proyectos señalados por Letelier, y que apuntaba a la resolución en parte de estas graves problemáticas nacionales existentes, es la construcción de un "Estado Docente", el cual pudiera ampliar la cobertura educacional (en especial en los sectores más desposeídos) y que 
construyera "un sistema educacional basado en la filosofía positivista y liberal, el cual se encontrara resguardado y avalado por el Estado, podría garantizar el desarrollo intelectual del país a pesar de las turbulencias políticas existentes" (Silva, 2010, pág. 60).

El proyecto de desarrollo tecnocrático se vio afianzado, no solo mediante la consolidación del apoyo de la clase media chilena a los tecnócratas, sino que también por una situación política particular que finalmente estalló en los años veinte del siglo pasado, la cual se caracterizó porque los grupos políticos fueron incapaces de realizar una gestión estatal que respondiera a las demandas sociales de los sectores medios y populares, y que paradójicamente, un gobierno de corte autoritario, fue el que genero un respaldo político institucionalizado para una verdadera "revolución tecnocrática", proyecto basado no solamente en la reafirmación de una idea de Estado racional y meritocrático que avalará la idea de un fuerte desarrollo educacional, el cual se vio consolidado en una primera instancia con la aprobación de la Ley de Instrucción Primaria Obligatoria de 1925. Sino que también generó una política eficientista en la administración de los asuntos del Gobierno, que sería la base para el desarrollo de una doctrina "desarrollista estatal".

Una herramienta fundamental para concretar esta idea fue la de descongestionar la administración central, mediante la descentralización de la toma de decisiones, la cual "por razones de carácter técnico se cree indispensable la descentralización o autonomía de un servicio con el fin de dotarlo de garantías más eficaces para obtener su cometido, sin las trabas del aparato administrativo tradicional o fiscal" (Correa Prieto, 1962, pág. 151).

Cabe señalar, que esta noción de un modelo desarrollista esbozado durante el gobierno de Ibáñez, se consolida también en los sucesivos gobiernos democráticos y principalmente con la llegada de Aguirre Cerda al poder, cuyo gobierno tenía entre sus ejes programáticos principales la generación de un "Estado industrializado", tarea en la cual los tecnócratas jugarían un rol fundamental. El pilar institucional básico para materializar este ideal, era la Corporación de Fomento de la Producción (CORFO), a la cual "se le asignan funciones que nunca antes tuvo algún organismo del Estado, como era la formulación de un plan productivo nacional y la consiguiente asignación de recursos de inversión" (Muñoz \& Arriagada, 1977, pág. 27).

Desde un principio, los tecnócratas se constituyeron en un grupo privilegiado al interior de la institución, este "nicho exclusivo" posibilitó que los agentes técnicos en la administración del plan de desarrollo económico e industrial, fueran los verdaderos constructores de un proyecto país en pro de la independencia económica y 
establecimiento del Sistema de Sustitución de Importaciones (ISI) en Chile, es más podemos asegurar que " el grupo tecnocrático de la CORFO elaboró una verdadera ideología de la industrialización, y se convirtió, de hecho, en el grupo de intelectuales orgánicos del proyecto de industrialización liderado por el gobierno. La cohesión ideológica de este grupo, se vio fortalecida por una formación profesional común y por la asimilación de una especie de "cultura del desarrollo", que hacia este grupo se reservara para sí la función de formular y aplicar las políticas de industrialización" (Muñoz \& Arriagada, 1977, pág. 52).

A modo de síntesis, es posible apreciar que los tecnócratas, no sólo han actuado meramente como un "brazo" administrativo de los designios de las grandes coaliciones políticas, sino que también se han constituido como una fuerza consciente de las necesidades nacionales y ha generado políticas en pos de las necesidades del pueblo chileno.

\section{Elementos tecnocráticos en la evolución de la Administración Pública chilena}

A lo largo de la evolución histórica de la tecnocracia en Chile, esta ha experimentado diferentes cambios en su formulación, producto de las diferentes tendencias en el conocimiento imperante y/o en la realidad social, económica y política de la nación. Es por esta razón, que es imprescindible realizar un análisis detallado de los diferentes elementos y/o doctrinas fundamentales para el desarrollo de los tecnócratas nacionales. Uno de los elementos imprescindibles, que pueden ayudar a establecer de forma consistente el desarrollo tecnocrático en la historia nacional, es la noción de "racionalidad", la cual es fundamental desde una perspectiva lógica, ya que es el pilar que fundamentó la inclusión de profesionales expertos en la administración del Estado.

Es más desde mediados del siglo XIX, el mismísimo Lastarria fue un férreo defensor de la noción cientificista en la gestión de los asuntos públicos, la cual no solamente era una reforma en el manejo de las temáticas del Estado, sino también una verdadera revolución contra los paradigmas de dominación política existentes, ya que "algunos intelectuales liberales de clase media adoptaron algunos de los postulados de la filosofía positivista de Comte y alzaron el estandarte de la razón científica en contra del sofocante orden oligárquico que dominaba a la sociedad chilena" (Silva, 2010, pág. 41). Cabe señalar, que desde este punto de vista la tecnocracia, no es solamente "una aplicación de métodos técnicos a la solución de problemas definidos, sino un ethos penetrante, una visión del mundo que subsume la estética, la religión, y el pensamiento tradicional bajo el modo racionalista" (Giddens, 1979, pág. 305) 
Por otra parte, la meritocracia constituyó uno de los pilares fundamentales, sobre el cual se cimentaba la elección de profesionales técnicos por sobre personas designadas por situación de clase y/o cuoteo político. La doctrina de elección en base al mérito, se basó en la aplicación de reformas significativas que tuvieron un efecto práctico y permanente sobre la elección de cargos públicos, ya que fue necesario "que se cambiaran las bases de admisión a los puestos públicos, estableciéndose requisitos que supusieran en los postulantes los conocimientos necesarios. Sólo la instauración de un serio proceso de selección podría garantizar la presencia de los mejores en el aparato público" (Silva, 2010, pág. 63)

A su vez, otro de los grandes discursos enarbolados por los profesionales tecnocráticos en la administración del Estado, fue un sentimiento ampliamente anti partidista (a pesar que algunos de ellos militaban en el radicalismo), como una forma de oposición clara a la influencia de los partidos políticos, que en base a una doctrina de carácter "clientelista" designaban autoridades en las diferentes reparticiones públicas y no en base a criterios meritocráticos, sino por razones netamente partidistas, alejadas de los ideales eficientistas de la tecnocracia. Es más durante el gobierno de Ibáñez, la incorporación de elementos tecnocráticos que pretendían desplazar a la élites políticas de la administración del Estado fue un hecho consumado, el cual "no sólo constituyó el desplazamiento de la vieja clase política, sino que también introdujo una serie de medidas necesarias para sanear al aparato público de una serie de vicios remanentes de los gobiernos anteriores, como el cohecho, o el clientelazgo político, por ejemplo; se impuso la carrera funcionaria como una forma de seleccionar a quienes hayan demostrados mayores aptitudes, competencia, y compromiso con su desempeño laboral” (Cárcamo, 2005, pág. 7).

Cabe señalar, que a pesar del alejamiento tácito (pero no expreso) de los tecnócratas con la política partidista tradicional, no significó que dichos profesionales se desentendieran de las necesidades nacionales del país, es más se comprometieron con proyectos estratégicos para el desarrollo nacional y fueron los promotores de la política de industrialización nacional.

En relación con este último punto, y como un ejemplo claro de que estos elementos que han configurado la noción de "tecnocracia" y se han vinculado efectivamente con proyectos de desarrollo nacional estratégicos, citaré el caso de la "política de industrialización nacional", llevada a cabo en la década de los años treinta, cuarenta y cincuenta del siglo pasado, y en especial la creación y consolidación de la Corporación de Fomento de la Producción (CORFO). El proyecto de la CORFO, fue una demostración clara de la consolidación de los ideales tecnocráticos materializados en la conformación de una institución bajo su propia dirección, lo que puede ser 
considerado "esencialmente como el resultado de los esfuerzos de los propios tecnócratas por obtener una mayor cuota de poder e influencia en detrimento de los políticos y de otros adversarios por el poder. Con este fin, los tecnócratas harían uso de sus credenciales técnicas, experiencia y prestigio profesional para obtener su objetivo político" (Silva, 2010, pág. 101). En la práctica, los cuerpos tecnocráticos dominaron ampliamente la formulación de políticas de fomento a la producción emanadas desde esta corporación, en base al rol que estos jugaron, ya que "los tecnócratas de la CORFO ocuparon una destacada posición de vanguardia, marcando pautas y el ritmo de la industrialización con más imaginación y audacia que los industriales del sector privado" (Silva, 2010, pág. 114).

A su vez, cabe destacar que este rol se vio ampliamente apoyado no solo por la coalición gobernante (Frente Popular), sino también en base a resultados de gestión inclusive por los grupos empresariales más conservadores, tal como se indicó en apartados anteriores.

\section{Conclusión}

Es evidente que el contexto institucional y político, en el cual los tecnócratas se vieron envueltos durante la primera mitad del siglo XX, posibilitaron que dicho grupo de profesionales pudiera posicionarse en la cúpula del manejo de los asuntos públicos, en desmedro de la clase política tradicional. También se puede afirmar que los tecnócratas fueron los autores intelectuales de la generación de las políticas del Estado de Bienestar en Chile, principalmente de la mano de gobiernos de carácter nacionalistas y/o populares (tales como los casos de Ibáñez y Aguirre, respectivamente), convenciendo a diferentes sectores ideológicos del proceso de industrialización nacional, en base a sus resultados macroeconómicos.

Por último, en materia de los principios tecnocráticos y su influencia en el desarrollo de la administración pública nacional, podemos destacar que su espíritu vinculado al mérito como forma ingreso al empleo público, los principios de racionalidad y eficiencia en materia económica y la despolitización de la toma de decisión respecto a las formas de implementación políticas públicas, generaron las bases de la administración pública nacional actual, la cual fuese más transparente, abierta a la posibilidad de que se integrasen los sectores medios profesionales a su gestión, con un mejor desarrollo en materia de uso de recursos y posibilitando la generación de proyectos nacionales en materia económica. 


\section{Referencias}

Cárcamo, J. (2005). Informe de Tesis: El Ideario Militar a partir de la Revolución de Septiembre, durante el primer gobierno de Carlos Ibáñez del Campo y su repercusión en la reforma estatal (1924-1931). Universidad de Chile.

Correa, L. (1962). El Presidente Ibáñez, la política y los políticos. Apuntes para la historia. Editorial del Pacífico.

Giddens, A. (1979). La estructura de clases en las sociedades avanzadas. Alianza.

Ibáñez Santa María, A. (1983). Los ingenieros, el Estado y la política en Chile. Del Ministerio de Fomento a la Corporación de Fomento. 1927-1939. Pontificia Universidad Católica de Chile.

Meynaud, J. (1968). Technocracy. Faber and Faber.

Muñoz, Ó., \& Arriagada, A. M. (1977). Origenes Politicos y Economicos del Estado Empresarial en Chile.

Silva, P. (2006). Los tecnócratas y la política en Chile: Pasado y Presente. Revista de Ciencia Política. 25, 175-190.

Silva, P. (2010). En el nombre de la razón: Tecnócratas y Política en Chile. Universidad Diego Portales.

\section{Diego Abel Durán Toledo}

Magíster en Gobierno y Gerencia Pública por la Universidad de Chile; Administrador Público (Universidad de Chile); Licenciado en Ciencias Políticas y Gubernamentales, mención Gestión Pública (Universidad de Chile); Diplomado en Normas Internacionales de Contabilidad del Sector Público (Universidad de Chile); Diplomado en Alta Gerencia (Politécnico de Colombia); Diplomado en Gestión Pública (Politécnico Superior de Colombia); Diplomado en Psicología Organizacional (Politécnico de Sudamérica) y Diplomado en Recursos Humanos y Desarrollo Organizacional (Universidad de Santiago de Chile). Secretario Académico de la carrera de Administración Pública de la Universidad Autónoma de Chile y Docente del Instituto Profesional AIEP. Asesor en Temas de Gestión Pública. 